\title{
Cervical Ripening and Induction of Labor: Awareness, Knowledge, Perception and Attitude of Antenatal Care-Seeking Women at Zagazig University Hospital, Zagazig, Egypt
}

\author{
Ahmed Mohamed Nooh ${ }^{*}$, Mohamed El-Sayed Mohamed ${ }^{2}$ \\ ${ }^{1}$ Obstetrics and Gynecology Department, Zagazig University Students' Hospital, Zagazig, Egypt \\ ${ }^{2}$ Obstetrics and Gynecology Department, Zagazig University Faculty of Medicine, Zagazig, Egypt \\ Email: ${ }^{*}$ ahmed.nooh@zu.edu.eg
}

Received 22 August 2015; accepted 18 September 2015; published 21 September 2015

Copyright (C) 2015 by authors and Scientific Research Publishing Inc.

This work is licensed under the Creative Commons Attribution International License (CC BY). http://creativecommons.org/licenses/by/4.0/

(c) (i) Open Access

\begin{abstract}
Objective: To assess awareness, knowledge and perceptions of antenatal care-seeking women about cervical ripening (CR) and induction of labor (IOL), and their attitude towards these interventions. Methods: An observational descriptive cross-sectional study which was conducted at an Egyptian teaching hospital. A questionnaire-based interview covered items on women's demographic and clinical data, as well as their awareness, knowledge, perception and attitude towards specific methods of CR and IOL. Results: A total of 853 questionnaires were analyzed, and 442 respondents (51.8\%) were aware of CR and IOL. Knowledge of Oxytocin use was noted in 215 participants (48.6\%), of membrane sweeping in $85(19.2 \%)$, of Foley's catheter in $110(24.9 \%)$ and of Misoprostol in $84(19.0 \%)$. The procedures were perceived to prevent cesarean section in 219 respondents (49.5\%). History of previous IOL was a predictor of awareness (OR: 5.19, 95\% CI: 1.6 11.23, $p=0.001^{*}$ ). Conclusion: This study showed that only a slightly more than $50 \%$ of participants were aware of CR and IOL, and the overall knowledge and perception were sub-optimal. Nevertheless, the attitudes towards the procedures were positive. Improved counselling is required in order to further increase knowledge about CR and IOL, and also correct misbelieves particularly in women at risk of undergoing IOL.
\end{abstract}

\section{Keywords}

Cervical Ripening, Induction of Labor, Awareness, Knowledge, Perception, Attitude

\footnotetext{
${ }^{*}$ Corresponding author.
}

How to cite this paper: Nooh, A.M. and Mohamed, M.E-S. (2015) Cervical Ripening and Induction of Labor: Awareness, Knowledge, Perception and Attitude of Antenatal Care-Seeking Women at Zagazig University Hospital, Zagazig, Egypt. Open Journal of Obstetrics and Gynecology, 5, 626-634. http://dx.doi.org/10.4236/ojog.2015.511088 


\section{Introduction}

Induction of labor (IOL) is defined as the interventional provocation of uterine contractions prior to the onset of spontaneous labor with the purpose of achieving vaginal delivery in a safe and timely manner [1]. Timing delivery for obstetrical, medical or social reasons has long been practised. Many folk beliefs concerning IOL are circulated among women in their final months of pregnancy, and several old midwives' tales that describe the use of enemas, castor oil and other laxatives, spices, sexual intercourse and exercise for this purpose, have long been around [2].

For decades, IOL has been a challenge to obstetricians, other maternity care givers, and most importantly mother and baby. It can often be a protracted process which makes providing patient-centered quality-care a great difficulty. This difficulty is expected to increase as the number of women undergoing IOL continues to increase [1].

Up to $50 \%$ of induced labors require cervical ripening [1]. This can be achieved using a variety of mechanical methods (amniotomy or artificial rupture of membranes-ARM, supra-cervical Foley's bulb catheter, laminaria tents... etc.), or pharmacologic/chemical methods (Oxytocin and synthetic prostaglandins). These methods can be used singly or in combination [1] [3]-[6].

The decision to induce labor should not be taken lightly because the process of IOL is not without risks. There should be a clear indication and benefits to mother, fetus or both which should outweigh the potential risks [7]. As such, IOL requires thorough counseling in order to meet women's expectations and ensure their satisfaction. The consequences of a failed IOL also need to be addressed [2] [7]. Three percent of CS's in a large Australian population-based study are being performed for failed IOL [8]. This rate is higher in other industrialized countries, with reports from Norway citing an induction failure rate of $4 \%$ [9] and about $10 \%$ in the USA [10].

The number of studies which have been conducted in Egypt assessing awareness, knowledge and perception of methods used for CR and IOL and the attitude towards these interventions among women attending antenatal clinic (ANC) is not accurately known, but is believed to be very little [11]. Knowledge of these variables is of paramount importance for the objective of guiding obstetricians and other maternity care givers in management of women in need for these interventions, and also for patient education purposes.

The objective of this study was, therefore, to assess awareness, knowledge and perception of specific methods used for CR and IOL and the attitude towards these interventions among antenatal care-seeking women, at Zagazig University Hospital (ZUH), Zagazig, Egypt.

\section{Subjects and Methods}

\subsection{Study Design}

This was a cross-sectional study which was conducted at the ANC, Obstetrics and Gynecology Department, ZUH, Zagazig, Egypt over the period from $28^{\text {th }}$ February to $30^{\text {th }}$ July 2015. Zagazig University Hospital Ethics Committee approved the study protocol. Women were counseled, a clear explanation of the study was given, and a written informed consent was then obtained from those who agreed to participate.

\subsection{Sample Size}

Usually, around 8500 deliveries per year are dealt with at ZUH. Using Epi-info, version 6 and based on a prevalence of IOL of 9.3\% in our environment and culture [12], a sample size calculation indicated that 844 participants have to be recruited to achieve a study power of $80 \%$ with $5 \%$ error and $95 \%$ confidence interval (95\% CI) in order to prove that the hypothesis is correct: there is a low level of awareness, knowledge and perception of CR and IOL among antenatal care-seeking women. However, allowing for exclusions for various reasons, the aim was to recruit 928 .

\subsection{Inclusion Criteria}

Women with the following conditions were eligible and approached for recruitment:

- a pregnancy at $\geq 36$ weeks gestation;

- a singleton fetus in cephalic presentation; and

- no contraindication for vaginal delivery. 


\subsection{Exclusion Criteria}

Women with the following conditions were ineligible and excluded:

- a pregnancy at $<36$ weeks gestation;

- a fetus in non-cephalic presentation;

- scarred uterus (including previous CS, myomectomy... etc.);

- multiple pregnancy; or

- placenta praevia or any other contraindication for vaginal delivery.

\subsection{Data Collection}

Participants were interviewed, and a structured purpose-designed questionnaire was filled. Anonymity of participating women and confidentiality of their responses were maintained by giving questionnaires numerical codes. The questionnaire covered information about demographic data. These included: age, education, occupation, religion, husband's education and occupation. Participants were then asked about their obstetric history which included date of last menstrual period, gestational age, parity, previous delivery, and previous CR and/or IOL-if any. Women's perceptions were judged by their concerns for the safety of the procedure. Participants' attitudes were assessed by the degree of satisfaction with previous IOL-if any, their willingness to undergo the procedure if indicated, future recommendation of CR and IOL to other women, and also by their desire for having teaching at ANC on when and how CR and IOL would be carried out. Participants were considered knowledgeable and aware of CR and IOL if they had ever heard about these interventions. Knowledge of $\geq 2$ methods was considered as high or adequate, while knowledge of only one method was deemed low or inadequate. Participating women with a prior knowledge about CR and IOL were asked about the sources of their knowledge, and whether these were relatives, friends, physicians, midwives or nurses, traditional birth attendants or any other source.Women who were interviewed had their antenatal hospital notes marked to avoid repeat recruitment during subsequent clinic visits. Recruitment continued until the statistically pre-determined sample size was reached.

\subsection{Statistical Analysis}

Data were analyzed using Statistical Package for Social Sciences version 20.0 (SPSS, Statistics for Windows, IBM Corp, Armonk, NY, USA). Qualitative data were presented by frequencies and percentages. The Chi-squared $\left(\chi^{2}\right)$ test was utilised for associations between categorical variables. Significant parameters were entered into a multivariate logistic regression model for determination of independent predictor variables. The level of statistical significance was $p \leq 0.05$.

\section{Results}

A total of 1023 women met the inclusion criteria. Out of these, 92 declined while the remaining 931 agreed to participate. However, 78 questionnaires were excluded as they were either incompletely or inappropriately filled. The remaining 853 questionnaires were thus analyzed for the purpose of this study.

Table 1 shows demographic and clinical data of all participants. Out of 81 participants who had previously had IOL, 29 women (35.8\%) regarded the information which has been given to them as insufficient and 8 (9.9\%) had an unsatisfactory experience during labour and delivery.

Table 2 shows awareness, knowledge and perception of all participants of CR and IOL and their attitude towards these interventions. Two hundred forty eight participants (29.1\%) of those who were aware about CR and IOL had the information passed to them from medical staff members, 127 (14.9\%) from nurses, 56 (6.6\%) from relatives or friends, while the remaining 11 women $(1.3 \%)$ had heard about the procedures from mass media (Television, Radio, Women's magazines... etc.).

Table 3 shows relevance of knowledge about CR and IOL to demographic and obstetric variables, while Table 4 shows logistic regression analysis.

\section{Discussion}

In this study, 81 participants (9.5\%) have had IOL in a previous pregnancy confirming that the procedure is not uncommon. The rate of IOL varies widely in different countries and units, and between individual obstetricians 
Table 1. Demographic and clinical data of all participants.

\begin{tabular}{|c|c|c|c|}
\hline \multirow{2}{*}{\multicolumn{2}{|c|}{ Variable }} & \multicolumn{2}{|c|}{ All participants $(n=853)$} \\
\hline & & $n$ & $\%$ \\
\hline \multirow{3}{*}{ Age (years) } & $19-25$ & 456 & 53.5 \\
\hline & $26-30$ & 262 & 30.7 \\
\hline & $31-37$ & 135 & 15.8 \\
\hline \multirow{2}{*}{ Education } & Secondary \& above & 228 & 26.7 \\
\hline & Primary \& below & 625 & 73.3 \\
\hline \multirow{2}{*}{ Occupation } & Employed & 282 & 33.1 \\
\hline & Unemployed & 571 & 66.9 \\
\hline \multirow{2}{*}{$\begin{array}{l}\text { Husband's } \\
\text { Education }\end{array}$} & Secondary \& above & 269 & 31.5 \\
\hline & Primary \& below & 584 & 68.5 \\
\hline \multirow{2}{*}{ Husband’s Occupation } & Skilled & 241 & 28.3 \\
\hline & Non-skilled & 612 & 71.7 \\
\hline \multirow{2}{*}{ Religion } & Muslim & 790 & 92.6 \\
\hline & Christian & 63 & 7.4 \\
\hline \multirow{2}{*}{ Parity } & 0 & 254 & 29.8 \\
\hline & $\geq 1$ & 599 & 70.2 \\
\hline \multirow{2}{*}{$\begin{array}{l}\text { Previous delivery } \\
\quad(n=599)\end{array}$} & VD & 412 & 48.3 \\
\hline & CS & 187 & 21.9 \\
\hline \multirow{2}{*}{ Previous IOL } & Yes & 81 & 9.5 \\
\hline & No & 772 & 90.5 \\
\hline
\end{tabular}

VD: Vaginal delivery; CS: Cesarean section; IOL: Induction of labor.

Table 2. Cervical ripening and induction of labor: awareness, knowledge, perception and attitude of participants.

\begin{tabular}{|c|c|c|c|c|}
\hline \multirow{2}{*}{\multicolumn{3}{|c|}{ Variable }} & \multicolumn{2}{|c|}{ All participants $(n=853)$} \\
\hline & & & $n$ & $\%$ \\
\hline \multirow{2}{*}{\multicolumn{2}{|c|}{ Awareness }} & Aware & 442 & 51.8 \\
\hline & & Not aware & 411 & 48.2 \\
\hline \multirow{5}{*}{\multicolumn{2}{|c|}{ Methods }} & Oxytocin IV & 215 & 48.6 \\
\hline & & Membrane sweeping & 85 & 19.2 \\
\hline & & Foley’s catheter & 110 & 24.9 \\
\hline & & Vaginal Misoprostol & 84 & 19.0 \\
\hline & & Others & 41 & 9.3 \\
\hline \multirow{14}{*}{ Knowledge $(n=442)$} & \multirow{7}{*}{ Indications } & Safe vaginal delivery & 278 & 62.9 \\
\hline & & Prevention of CS & 219 & 49.5 \\
\hline & & Preparation for CS & 184 & 41.6 \\
\hline & & Hospital staff convenience & 123 & 27.8 \\
\hline & & Prevention of IUFD & 321 & 72.6 \\
\hline & & Prevention of PPH & 239 & 54.1 \\
\hline & & Don’t know & 84 & 19.0 \\
\hline & \multirow{5}{*}{ Complications } & Prolonged labour & 141 & 31.9 \\
\hline & & More pain during labour & 189 & 42.8 \\
\hline & & Dangerous to baby & 234 & 52.9 \\
\hline & & Dangerous to mother & 280 & 63.3 \\
\hline & & Increased CS rate & 28 & 6.3 \\
\hline & \multirow{2}{*}{ Level of knowledge } & Adequate ( $\geq$ score median) & 193 & 43.7 \\
\hline & & Inadequate (<score median) & 249 & 56.3 \\
\hline \multirow{2}{*}{\multicolumn{2}{|c|}{$\begin{array}{l}\text { Attitude } \\
(n=442)\end{array}$}} & Positive attitude & 311 & 70.4 \\
\hline & & Negative attitude & 131 & 29.6 \\
\hline
\end{tabular}

IV: Intra-venous; CS: Cesarean section; IUFD: Intra-uterine fetal death; PPH: Post-partum hemorrhage; Positive attitude: Would accept IOL if indicated or would recommend IOL to others, or both; Negative attitude: Would not accept IOL if indicated or would not recommend IOL to others, or both. 
Table 3. Knowledge: cross tabulation with demographic and obstetric variables.

\begin{tabular}{|c|c|c|c|c|c|c|}
\hline \multirow{3}{*}{\multicolumn{2}{|c|}{ Demographic and obstetric variables }} & \multicolumn{4}{|c|}{ Knowledge $(n=442)$} & \multirow{3}{*}{$P$} \\
\hline & & \multicolumn{2}{|c|}{$\begin{array}{l}\text { Adequate } \\
(n=193)\end{array}$} & \multicolumn{2}{|c|}{$\begin{array}{c}\text { Inadequate } \\
(n=249)\end{array}$} & \\
\hline & & $n$ & $\%$ & $n$ & $\%$ & \\
\hline \multirow{3}{*}{ Age group (years) } & $19-25$ & 33 & 17.1 & 45 & 18.1 & \multirow{3}{*}{0.96} \\
\hline & $26-30$ & 101 & 52.3 & 128 & 51.4 & \\
\hline & $31-37$ & 59 & 30.6 & 76 & 30.5 & \\
\hline \multirow{2}{*}{ Education } & Secondary \& above & 60 & 31.1 & 80 & 32.1 & \multirow{2}{*}{0.81} \\
\hline & Primary \& below & 133 & 68.9 & 169 & 67.9 & \\
\hline \multirow{2}{*}{ Occupation } & Employed & 81 & 42.0 & 95 & 38.2 & \multirow{2}{*}{0.41} \\
\hline & Unemployed & 112 & 58.0 & 154 & 61.8 & \\
\hline \multirow{2}{*}{ Husband's Education } & Secondary \& above & 52 & 27.0 & 60 & 24.1 & \multirow{2}{*}{0.49} \\
\hline & Primary \& below & 141 & 73.0 & 189 & 75.9 & \\
\hline \multirow{2}{*}{ Husband's Occupation } & Skilled & 82 & 42.5 & 70 & 28.1 & \multirow{2}{*}{$0.001^{* *}$} \\
\hline & Not skilled & 111 & 57.5 & 179 & 71.9 & \\
\hline \multirow{2}{*}{ Religion } & Muslim & 178 & 92.2 & 223 & 89.6 & \multirow{2}{*}{0.33} \\
\hline & Christian & 15 & 7.8 & 26 & 10.4 & \\
\hline \multirow{2}{*}{ Parity } & Nullipara & 41 & 21.2 & 129 & 51.8 & \multirow{2}{*}{$0.00^{* *}$} \\
\hline & Multipara & 152 & 78.8 & 120 & 48.2 & \\
\hline \multirow{2}{*}{ Previous delivery } & VD & 127 & 65.8 & 78 & 31.3 & \multirow{2}{*}{$0.00^{* *}$} \\
\hline & CS & 25 & 13.0 & 42 & 16.9 & \\
\hline \multirow{2}{*}{ Previous IOL } & Yes & 73 & 37.8 & 8 & 3.2 & \multirow{2}{*}{$0.00^{* *}$} \\
\hline & No & 120 & 62.2 & 241 & 96.8 & \\
\hline
\end{tabular}

VD: Vaginal delivery; CS: Cesarean section; IOL: Induction of labor.

Table 4. Multivariate logistic regression for inadequate knowledge predictors.

\begin{tabular}{|c|c|c|c|c|}
\hline \multicolumn{2}{|c|}{ Variable } & OR & $95 \%$ CI & $P$ \\
\hline \multirow{2}{*}{ Husband's Occupation } & Skilled & (Ref) & & \\
\hline & Non-skilled & 2.45 & $0.85-124.6$ & 0.087 \\
\hline \multirow{2}{*}{ Parity } & Nullipara & 1.91 & $0.21-5.68$ & 0.074 \\
\hline & Multipara & (Ref) & & \\
\hline \multirow{2}{*}{ Previous delivery } & VD & (Ref) & & \\
\hline & CS & 1.54 & $0.24-124.3$ & 0.24 \\
\hline \multirow{2}{*}{ Previous IOL } & Yes & (Ref) & & \\
\hline & No & 5.19 & $1.6-11.23$ & $0.001 *$ \\
\hline
\end{tabular}

VD: Vaginal delivery; CS: Cesarean section; IOL: Induction of labor; OR: Odds ratio; 95\% CI: 95\% Confidence interval.

within the same unit, and the reasons for this variability are not clear. However, such variation may be due to differences in the incidence of the indications for induction, lack of agreement on characterization of definition of various indications (e.g. of post-maturity or hypertension), differences in availability of resources, as well as to unexplained differences in opinion and practice. Nevertheless, there is no agreement or evidence to suggest an ideal rate [13]. The number of women whose labours are induced has risen dramatically over the past two decades. Rates in the USA and the UK currently exceed 20\% of all births [3] [5] [14] [15]. Even further, in some 
units in the USA, up to 50\% of all births follow IOL [15]. However, researchers reporting from African countries have noted rates of $<10 \%$; albeit showing the same worldwide trend of progressive increase [12] [16].

In this study, 442 participants (51.8\%) were aware of CR and IOL. However, the overall knowledge was sub-optimal; especially regarding membrane sweeping [only 85 women out of 442 (19.2\%) heard about it], and use of vaginal misoprostol [only 84 women $(19.0 \%)$ were aware of it]. Perception was also sub-optimal as 84 out of 442 respondents (19.0\%) were not aware of the indications of CR and IOL, and only 219 (49.5\%) believed that IOL prevents CS.

Antenatal healthcare givers constitute a major source of awareness of and knowledge about CR and IOL for pregnant women. Shortage of their services, combined with low level of women's education, is to be blamed for the relatively low level of awareness exhibited in this study. Poor knowledge of specific procedures and methods, and incorrect perceptions may also be related to difficulties of participants' recall, inadequate content of health education sessions or clinic consultation and lack of previous exposure [17]. The later may also explain why, in this study, knowledge was higher in women with a previous history of CR and IOL.

In this study, the most well-known method of IOL was intravenous Oxytocin which is also the commonest agent used for IOL worldwide. It has been used alone, in combination with ARM or following CR with other pharmacological or non-pharmacological methods. Prior to the introduction of prostaglandin agents, Oxytocin was used as a cervical ripening agent as well. In developed countries Oxytocin alone is more commonly used in the presence of ruptured membranes whether spontaneous or artificial. In developing countries where the incidence of HIV is high, delaying ARM in labor reduces vertical transmission rates and hence the use of Oxytocin with intact membranes warrants further investigation [18] [19].

The majority of participating women in this study were not aware of Misoprostol use for CR and IOL despite its widespread use among Obstetricians and Gynaecologists in Egypt [20] [21]. Misoprostol is a synthetic form of prostaglandin E1 analogue which has gained popularity in obstetrics and gynaecology worldwide. Although not licensed for CR and IOL in many parts of the world, Misoprostol is licensed for this indication in Egypt. However, the drug is not without complications. Rates of uterine hyper-stimulation, uterine rupture, serious CTG abnormalities, meconium stained liquor and neonatal hypoxic ischemic encephalopathy were increased with Misoprostol use especially at doses above $25 \mu \mathrm{g}$ [22].

In this study, 189 participants out of 442 (42.8\%) considered that labour following IOL was more painful. This perception may be due to one or more of several reasons. Only limited choices of pain relief in labor are available in Egypt; a developing country with limited resources. Induced labor significantly differs from the physiological spontaneous onset labor, with a longer and often painful latent phase. Prostaglandins may be associated with significant discomfort. Simple analgesia may suffice, but some women will require stronger opiate or epidural analgesia [23].

In Egypt, use of different methods of pain relief in labor has been extensively investigated. It was noted that women who had IOL equally benefited from the available limited options of pain relief in labor as those who came in spontaneous labor. Nevertheless, there is still an unmet need for obstetric analgesia among many women all-over the country. Large governmental maternity hospitals in Egypt are facing serious challenges in providing care that is of consistently high quality in a rapidly changing and unstable environment. [11] [24].

Women who are induced tend to be less satisfied with their experience of childbirth [25]. In this context, and with increasing pressure on healthcare resources, it is particularly important to address questions about how to provide safe IOL in settings and ways that are acceptable to women, and in the most possible cost-effective way [15]. Counselling about the cascade of events following IOL and its complications has been perceived as inadequate by parturients [25] [26]. Heimstad et al., found that women who had IOL were not satisfied with the information they were given and desired more participation in decision-making [27]. The finding which was reported by the majority of respondents [311 out of 442 (70.4\%)] in this study of willingness to accept IOL in the index pregnancy or recommend it to somebody else despite concerns about pain and harm to baby and mother, is perplexing. Especially in developing countries, there is the possibility that willingness to re-experience a procedure is influenced by the recommendations of medical staff members whose knowledge and guidance may completely overwhelm maternal wishes [2]. Maternal autonomy has been noted to be influenced by fear of physician's negative attitude and reaction to refusal, the probability of occurrence of adverse consequences and/or abandonment of care should doctors' advice and recommendations be not followed [28].

In this study, all participating women wanted IOL to be included among antenatal health education topics. However, the matter should be thoroughly studied in order to determine the content of the IOL educational 
messages since untested information about risks of CR and IOL may scare women from the procedures when they are genuinely indicated [2]. Nevertheless, the messages must address the issues of safety and woman's refusal since 280 out of 442 respondents (63.3\%), in this study, perceived IOL as dangerous to mother, 234 (52.9\%) considered it dangerous to baby and 131 (29.6\%) would refuse CR and IOL even when indicated. All participants in this study desired to be told the specific indication for IOL when indicated for the purpose of their satisfaction. The reported dislike of women to IOL in this study may not be due to fear of the procedure as such, but it may represent a reflection of their wishes to have spontaneous onset of labor which they deem natural. This desire has been expressed by women both in developing and developed countries [29] [30].

In this study, women who has not had a previous IOL were more than five times unaware about CR and IOL (OR: 5.19; 95\% CI: $1.6-11.23 ; p=0.001^{*}$ ). This is in agreement with Enabor et al., who noted that participants who had a previous IOL were more than six times more aware about CR and IOL (OR: 6.70; 95\% CI: 1.41 31.88, $p=0.02)[2]$.

\section{Conclusion}

This study has shown that a slightly more than half of participants were aware of CR and IOL, and the overall knowledge and perception were sub-optimal. Nevertheless, the attitudes towards CR and IOL were positive, if the procedures were indicated. Women's knowledge of specific methods of CR and IOL and their indications should be further enhanced by improving antenatal clinic services. This health education duty can be achieved through parent craft classes, patient information leaflets and the different multimedia tools. Emphasis should be given to securing enough time for counselling sessions targeting women who are more likely to undergo CR and IOL, with information being part of their birth preparedness plan. Communication skills of medical, midwifery and nursing staff should be continuously developed for this purpose. With the increased use of Misoprostol in obstetrics, women should be given more information about its indications and possible complications. More options of obstetric analgesia, in the context of available resources, should be offered to women in order to dispel their fears of pain and improve their level of satisfaction with the birth process.

\section{Acknowledgements}

The authors would like to thank junior medical, midwifery and nursing staff of Obstetrics and Gynecology Department at ZUH for their contribution to collection of the data of this study.

\section{Declaration of Interest}

The authors report no conflicts of interest.

\section{Role of the Funding Source}

The authors alone were responsible for funding this work. They have not received any grants, financial support or any other source of funding.

\section{References}

[1] Stephenson, M.L. and Wing, D.A. (2015) A Novel Misoprostol Delivery System for Induction of Labor: Clinical Utility and Patient Considerations. Drug Design, Development and Therapy, 9, 2321-2327.

[2] Enabor, O.O., Olayemi, O.O., Bello, F.A., et al. (2012) Cervical Ripening and Induction of Labour-Awareness, Knowledge and Perception of Antenatal Attendees in Ibadan, Nigeria. Journal of Obstetrics and Gynaecology, 32, 652-656. http://dx.doi.org/10.3109/01443615.2012.657271

[3] Carbone, J.F., Tuuli, M.G., Fogertey, P.J., et al. (2013) Combination of Foley Bulb and Vaginal Misoprostol Compared with Vaginal Misoprostol Alone for Cervical Ripening and Labor Induction: A Randomized Controlled Trial. Obstetrics \& Gynecology, 121, 247-252.

[4] Austin, S.C., Sanchez-Ramos, L. and Adair, C.D. (2010) Labor Induction with Intravaginal Misoprostol Compared with the Dinoprostone Vaginal Insert: A Systematic Review and Meta-Analysis. American Journal of Obstetrics and Gynaecology, 202, 624.e1-624.e9. http://dx.doi.org/10.1016/j.ajog.2010.03.014

[5] Hofmeyr, G.J. (2003) Induction of Labour with an Unfavourable Cervix. Best Practice and Research Clinical Obstetrics and Gynaecology, 17, 777-794. http://dx.doi.org/10.1016/S1521-6934(03)00037-3 
[6] Olson, D.M. (2003) The Role of Prostaglandins in the Initiation of Parturition. Best Practice and Research Clinical Obstetrics and Gynaecology, 17, 717-730. http://dx.doi.org/10.1016/S1521-6934(03)00069-5

[7] Talaulikar, V.S. and Arulkumaran, S. (2011) Failed Induction of Labor: Strategies to Improve the Success Rates. Obstetrical \& Gynecological Survey, 66, 717-728. http://dx.doi.org/10.1097/ogx.0b013e31823e0c69

[8] Mealing, N.M., Roberts, C.L., Ford, J.B., et al. (2009) Trends in Induction of Labour, 1998-2007: A Population-Based Study. Australian and New Zealand Journal of Obstetrics and Gynaecology, 49, 599-605. http://dx.doi.org/10.1111/j.1479-828X.2009.01086.x

[9] Kolas, T., Hofoss, D., Daltveit, A.K., et al. (2003) Indications for Cesarean Deliveries in Norway. American Journal of Obstetrics \& Gynecology, 188, 864-870. http://dx.doi.org/10.1067/mob.2003.217

[10] Spong, C.Y., Berghella, V., Wenstrom, K.D., et al. (2012) Preventing the First Cesarean Delivery: Summary of a Joint Eunice Kennedy Shriver National Institute of Child Health and Human Development, Society for Maternal-Fetal Medicine, and American College of Obstetricians and Gynecologists Workshop. Obstetrics \& Gynecology, 120, 11811193.

[11] Abdel-Ghani, R.M. and Berggren, V. (2011) Parturient Needs during Labor: Egyptian Women’s Perspective toward Childbirth Experience, a Step toward an Excellence in Clinical Practice. Journal of Basic and Applied Scientific Research, 1, 2935-2943.

[12] Abdel-Aleem, H. (2011) Misoprostol for Cervical Ripening and Induction of Labour: RHL Commentary. The WHO Reproductive Health Library, World Health Organization (WHO), Geneva.

[13] Nooh, A., Baghdadi, S. and Raouf, S. (2005) Induction of Labour: How Close to the Evidence-Based Guidelines Are We? Journal of Obstetrics and Gynaecology, 25, 451-454. http://dx.doi.org/10.1080/01443610500160121

[14] Hamilton, B.E., Martin, J.A. and Ventura, S.J. (2013) Births: Preliminary Data for 2012. National Vital Statistics Reports, 62, 1-20.

[15] Dowswell, T., Kelly, A.J., Livio, S., Norman, J.E. and Alfirevic, Z. (2010) Different Methods for the Induction of Labour in Outpatient Settings. Cochrane Database of Systematic Reviews, No. 8, Article ID: CD007701. http://dx.doi.org/10.1002/14651858.cd007701.pub2

[16] Afolabi, B.B., Oyeneyin, O.L. and Ogendengbe, O.K. (2005) Intravaginal Misoprostol versus Foley Catheter for Cervical Ripening and Induction of Labour. International Journal of Gynaecology and Obstetrics, 89, 263-267. http://dx.doi.org/10.1016/j.ijgo.2005.02.010

[17] Al-Ateeq, M.A. and Al-Rusaiess, A.A. (2015) Health Education during Antenatal Care: The Need for More. International Journal of Women's Health, 7, 239-242. http://dx.doi.org/10.2147/IJWH.S75164

[18] Alfirevic, Z., Kelly, A.J. and Dowswell, T. (2009) Intravenous Oxytocin Alone for Cervical Ripening and Induction of Labour. Cochrane Database of Systematic Reviews, No. 4, Article ID: CD003246. http://dx.doi.org/10.1002/14651858.cd003246.pub2

[19] Kelly, A.J. and Tan, B. (2001) Intravenous Oxytocin Alone for Cervical Ripening and Induction of Labour. Cochrane Database of Systematic Reviews, No. 3, Article ID: CD003246. http://dx.doi.org/10.1002/14651858.cd003246

[20] Abdellah, M.S., Hussien, M. and Aboalhassan, A. (2011) Intravaginal Administration of Isosorbidemononitrate and Misoprostol for Cervical Ripening and Induction of Labour: A Randomized Controlled Trial. Archives of Gynecology and Obstetrics, 284, 25-30. http://dx.doi.org/10.1007/s00404-010-1572-4

[21] Habib, S.M., Emam, S.S. and Saber, A.S. (2008) Outpatient Cervical Ripening with Nitric Oxide Donor Isosorbidemononitrate Prior to Induction of Labor. International Journal of Gynecology \& Obstetrics, 101, 57-61. http://dx.doi.org/10.1016/j.ijgo.2007.09.027

[22] Elati, A. and Weeks, A. (2009) The Use of Misoprostol in Obstetrics and Gynaecology. BJOG, 116, 61-69. http://dx.doi.org/10.1111/j.1471-0528.2009.02329.x

[23] Goel, K., Gedam, J.K., Rajput, D.A. and Bhalerao, M.V. (2014) Induction of Labor: A Review. Indian Journal of Clinical Practice, 24, 1057-1064.

[24] Abdel-Barr, T., Elshalakany, N.A. and Shafik, Y.M. (2014) Single Dose Spinal Analgesia: Is It a Good Alternative to Epidural Analgesia in Controlling Labour Pain? Egyptian Journal of Anaesthesia, 30, 241-246. http://dx.doi.org/10.1016/j.egja.2014.02.003

[25] Shetty, A., Burt, R., Rice, P. and Templeton, A. (2005) Women’s Perceptions, Expectations and Satisfaction with Induced Labour-A Questionnaire-Based Study. European Journal of Obstetrics \& Gynecology and Reproductive Biology, 123, 56-61. http://dx.doi.org/10.1016/j.ejogrb.2005.03.004

[26] Simpson, K.R. and Atterbury, J. (2003) Trends and Issues in Labour Induction in the United States: Implications for Clinical Practice. Journal of Obstetric Gynaecological and Neonatal Nursing, 32, 767-769. http://dx.doi.org/10.1177/0884217503258528 
[27] Heimstad, R., Romundstad, P.R., Hyett, J., Mattsson, L.-Å. and Salvesen, K.Å. (2007) Women’s Experiences and Attitudes towards Expectant Management and Induction. Acta Obstetrics and Gynaecology Scandinavia, 86, 950-956. http://dx.doi.org/10.1080/00016340701416929

[28] Chigbu, C.O. and Ezenyeaku, C.C. (2008) Women's Opinions and Experiences with Induction of Labour and Caesarean Delivery on Request in South Eastern Nigeria. International Journal of Gynaecology and Obstetrics, 103, 158-161. http://dx.doi.org/10.1016/j.ijgo.2008.06.006

[29] Aziken, M., Omo-Aghoja, L. and Okonofua, F. (2007) Perceptions and Attitudes of Pregnant Women towards Caesarean Section in Urban Nigeria. Acta Obstetrics and Gynaecology Scandinavia, 86, 42-47. http://dx.doi.org/10.1080/00016340600994950

[30] Angeja, A.C., Washington, A.E., Vargas, J.E., Gomez, R., Rojas, I. and Caughey, A.B. (2006) Chilean Women's Preferences Regarding Mode of Delivery: Which Do They Prefer and Why? BJOG, 113, 1253-1258. http://dx.doi.org/10.1111/j.1471-0528.2006.01069.x 